\title{
Azospirillum brasilense and Saccharomyces cerevisiae as Alternative for Decrease the Effect of Salinity Stress in Tomato (Lycopersicon esculentum) Growth
}

\author{
Ali Abdelmoteleb ${ }^{1}$, Daniel Gonzalez-Mendoza ${ }^{2, *}$ and Ahmed Mohamed Elbaalawy ${ }^{3}$ \\ ${ }^{1}$ Botany Department, Faculty of Agriculture, Menoufia University, Shebin El-Kom, Po 32511, Egypt \\ ${ }^{2}$ Instituto de Ciencias Agrícolas, Universidad Autónoma de Baja California, Carretera a Delta s/n Ejido Nuevo León, Baja California, \\ CP 21705, México \\ ${ }^{3}$ Department of Soil Science, Faculty of Agriculture, Menoufia University, Shebin El-Kom, Po 32511, Egypt \\ *Corresponding Author: Daniel Gonzalez-Mendoza. Email: danielg@uabc.edu.mx
}

Received: 18 February 2021 Accepted: 17 May 2021

\begin{abstract}
The salinity stress is one of the most relevant abiotic stresses that affects the agricultural production. The present study was performed to study the improvement of the salt tolerance of tomato plants which is known for their susceptibility to salt stress. The present study aimed to assess to what extent strain Azospirillum brasilense (N040) and Saccharomyces cerevisiae improve the salt tolerance to tomato plants treated with different salt concentration. The inoculant strain A. brasilense (N040) was previously adapted to survive up to $7 \% \mathrm{NaCl}$ in the basal media. A greenhouse experiment was conducted to evaluate the effect of this inoculation on growth parameter such as: plant height, root length, fresh and dry weight, fruits fresh weight, chlorophyll content, proline and total soluble sugar in tomato plants under salt stress condition. The results revealed that co-inoculation of Azospirillum brasilense (N040) and Saccharomyces cerevisiae significantly increased the level of proline (8.63 mg/g FW) and total soluble sugar $(120 \mathrm{mg} / \mathrm{g} \mathrm{FW})$ of leaves under salinity condition comparing to non-inoculated plants $(2.3 \mathrm{mg} / \mathrm{g} \mathrm{FW}$ and $70 \mathrm{mg} / \mathrm{g} \mathrm{FW}$, respectively). Plants co-inoculated with adapted strain of A. brasilense and S. cerevisiae showed the highest significant $(p<0.01)$ increase in fruit yield $(1166.6 \mathrm{~g} / \mathrm{plant})$, plant high $(115 \mathrm{~cm})$ and roots length (52.6) compared whit un-inoculated control plants $(42 \mathrm{~g} / \mathrm{pant}, 43.3 \mathrm{~cm}$ and $29.6 \mathrm{~cm}$, respectively). In contrast, $\mathrm{Na}^{+}$ion content was significantly decreased in the leaves of salt stressed plants treated with the A. brasilense (N040) and S. cerevisiae. Finally, the results showed that dual benefits provided by both A. brasilense (N040) and $S$. cerevisiae can provide a major way to improve tomato yields in saline soils.
\end{abstract}

\section{KEYWORDS}

Salinity stress; tomato; proline; exopolysaccharides; microorganism

\section{Introduction}

Salinity represents the major challenge of agricultural production and sustainable agricultural systems worldwide due to increasingly salinization that occurs naturally and throug $\mathrm{h}$ anthropogenic processes such as leaching and insufficient drainage of irrigation water [1,2]. Salinity stress caused by $\mathrm{NaCl}$ is one of the most common abiotic stress that affected the plant productivity as results of morphological (e.g., reduction in leaves number and fruit production) and metabolic disorder (e.g., nutrient ion 
imbalance, decrease in stomatal conductance, low photosynthetic activity) [3]. According to Shrivastava et al. [4], different strategies have been developed to reduce the adverse effects caused by salinity stress on plant physiology (e.g., physical and chemical methods and plant genetic engineering). Different author has demonstrated that beneficial microorganism plays a significant role in alleviating salt stress in plants, resulting in increased crop yield [5]. Plant-growth-promoting rhizobacteria (PGPR) are a group of microorganisms that colonize plant's roots or free-living organisms that directly or indirectly enhance the growth of plants [6]. For example, the production of indole acetic acid, gibberellins and some unknown determinants by PGPR, results in increased root length, root surface area and number of root tips, leading to an enhanced uptake of nutrients thereby improving plant health under stress conditions [7]. The inoculation of plants with PGPR such as Azospirillum can play a vital role to mitigate salt toxicity in plants through enhancing nutrient uptake and reduction of harmful effects of salt stress via accumulating osmolytes (osmo-protectants) such as soluble sugars, potassium, production of exopolysaccharides (EPS) and proline in plants $[8,9]$.

The application of Azospirillum is an alternative approach, eco-friendly that contribute to the plant response regulation of salt stress increasing agriculture productivity [10]. The growth stimulation of tomato, rapeseed, pepper and corn plants under salt stress by inoculation with PGPR has been reported $[9,11]$. Tomato (Solanum lycopersicum) is one of the best crops to study salt tolerance in the dicotyledonous crops due to its well-known genetics [12]. High salinity adversely affects seed germination and inhibit growth and fruit development in tomato. Therefore, the alleviation of adverse effects of salinity on tomato plants will significantly impact the enhancement of vegetable productivity, particularly in arid and semi-arid regions.

This study extends our understanding of microbially mediated systemic tolerance in plants and motivates us to use microbial inoculants for the reclamation of salt lands. Therefore, this work was conducted to adapt $A$. brasilense to high salt concentrations and investigate PGPR properties of adapted strain under different salinity levels. It also evaluated the ability of wild type and adapted strain of A. brasilense in single inoculants and combined with Saccharomyces cerevisiae to alleviate harmful effect of salinity, and their role in enhancing tomato growth and yield under salt stress in a greenhouse experiment. We propose a positive outcome of tomato plants interaction with $A$. brasilense and $S$. cerevisiae during salt stress and represent a promising way to improve tolerance of this plant's productivity in saline soils.

\section{Materials and Methods}

\subsection{Microorganism Strains Used in the Experiment}

Azospirillum brasilense NO40 was obtained from Microbiology Dep., Soil, Water and Environmental Research Institute, Agriculture Research Center. Saccharomyces cerevisiae Y-389 were kindly received from the National center for Agriculture Utilization Research, USDA, Illinois, USA.

\subsection{Sequential Adaptation Approach}

For the preparation of bacterial inoculum, the culture was grown up to a mid-exponential growth phase in nutrient broth and then, the grown bacterial culture was centrifuged, the cell pellets were washed and

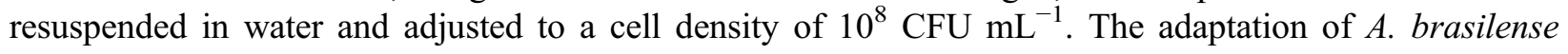
NO40 for tolerance to high salt concentration was conducted through the sequential transfers approach with gradually increasing salt concentration in the culture media [13]. Overnight bacterial culture was inoculated in liquid media supplemented with $2 \% \mathrm{NaCl}$ and incubated at $30 \pm 2{ }^{\circ} \mathrm{C}$ and $130 \mathrm{rpm}$ for three days. After incubation, the grown culture was inoculated with a cell density of $10^{7} \mathrm{CFU} \mathrm{mL}^{-1}$ into fresh liquid media containing $2 \% \mathrm{NaCl}$ under the same growth conditions, followed by three such transfers. Part of the earlier bacterial culture was inoculated in fresh media increasing $\mathrm{NaCl}$ concentration to $3 \%$, 
followed by three such sequential transfers in fresh media under similar growth conditions. The sequential transfer strategy was used for bacterial adaptation to $4 \%, 5 \%, 6 \%$ and $7 \% \mathrm{NaCl}$ by the same approach. The bacterial growth rate for each $\mathrm{NaCl}$ concentration was quantified in triplicates by measuring the optical density (OD) at $600 \mathrm{~nm}$. Finally, the adapted culture was re-isolated on agar plates, and then a single colony was picked up and cultivated in liquid media to store in $30 \%$ glycerol at $-20^{\circ} \mathrm{C}$. To confirm adapted bacteria's stability to high salt concentration, an aliquot of frozen glycerol stock was taken after $30,45,60$ and 75 days of preservation, and grown in broth media with zero additional salt. The bacterial culture was transferred once into the same media, and then transferred into a growth medium containing $\mathrm{NaCl}(7 \%)$.

\subsection{Acetylene Reduction Assay (ARA) under Salinity Condition}

The quantitative estimation of nitrogenase enzyme activity was conducted by gas chromatography (GC) [9]. ARA was determined by Hewlett Packard chromatograph (Hp 6890 GC) fitted with a dual flame detector and a $150 \mathrm{~cm} \times 0.4 \mathrm{~cm}$ diameter stainless steel column fitted with a Propa XR 100-120 mesh. The adaptive bacteria inoculated the tubes $(7 \mathrm{~mL}$ capacity) containing $3 \mathrm{~mL}$ nitrogen-free broth media amended with different concentrations of $\mathrm{NaCl}$. The tubes were stoppered with cotton plugs, and then exchanged with rubber stoppers after observing visible bacterial growth.

The air (gas phase) in the headspace was replaced with acetylene $10 \%(\mathrm{v} / \mathrm{v})$, and after incubation in the dark at $28^{\circ} \mathrm{C}$, the ethylene production was measured, and ARA was expressed as $\mu \mathrm{moL}$ of $\mathrm{C}_{2} \mathrm{H}_{4} / \mathrm{mg}$ protein/h.

\subsection{Quantification of IAA Production under Salinity Condition}

Quantitative estimation of IAA production by the adaptive tolerance bacteria was determined in the presence of $0 \%, 1 \%, 3 \%, 5 \%$ and $7 \% \mathrm{NaCl}$ concentration in the growth media. $50 \mathrm{~mL}$ broth media supplemented with L-Tryptophan $(100 \mathrm{mg} / \mathrm{L})$ was inoculated with $1 \mathrm{~mL}$ overnight bacterial culture and incubated at $30 \pm 2{ }^{\circ} \mathrm{C}$ for 3 days $150 \mathrm{rpm}$ under dark condition. After incubation time, the cultures were centrifuged at $12000 \mathrm{rpm}$ for $10 \mathrm{~min}$ at $4^{\circ} \mathrm{C}$. IAA was measured through mixing $1 \mathrm{~mL}$ of culture supernatant with $2 \mathrm{~mL}$ of Salkowski reagent $\left(2 \% 0.5 \mathrm{M} \mathrm{FeCl}_{3}\right.$ in $35 \%$ perchloric acid); and incubated the mixture in the dark for $30 \mathrm{~min}$ at room temperature for pink color development as an indicator of IAA production. The optical density of color was spectrophotometrically measured at $530 \mathrm{~nm}$, and a standard curve of authentic IAA was used for calibration of the quantity of produced IAA [14].

\subsection{Production of Exopolysaccharides (EPS) by Adapted Bacteria under Salt Condition}

The adapted bacteria were inoculated in $250 \mathrm{~mL}$ Erlenmeyer flasks containing $100 \mathrm{~mL}$ broth media supplemented with $0 \%, 1 \%, 3 \%, 5 \%$ and $7 \% \mathrm{NaCl}$ at $28^{\circ} \mathrm{C}$ and $150 \mathrm{rpm}$ for 3 days of incubation. After incubation, the supernatant was collected by centrifugation at $7000 \mathrm{rpm}$ and $4{ }^{\circ} \mathrm{C}$ for 15 min to remove the bacterial cells. Crude EPS was prepared by mixing the supernatant with two volumes of absolute ethanol at $4^{\circ} \mathrm{C}$ for 2 days, and then the mixture was centrifuged at $8000 \mathrm{rpm}$ and $4^{\circ} \mathrm{C}$ for $15 \mathrm{~min}$. EPS solution was prepared by re-suspending crude EPS with distilled water. The sugar content was assessed via phenol sulfuric acid scheme by mixing $200 \mu \mathrm{L}$ of EPS solution with $200 \mu \mathrm{L}$ of phenol solution (5\%), then addition $1 \mathrm{~mL}$-sulfuric acid solution. After $15 \mathrm{~min}$ at room temperature, the optical density of the mixture was measured at $490 \mathrm{~nm}$. The results were compared to glucose standard curve to quantify the EPS concentrations [15].

\subsection{Greenhouse Experiment}

Green house experiment was carried out in the faculty of agriculture, Menoufia University, Egypt; to evaluate wild-type and adapted $A$. brasilense inoculation on growth and yield of tomato plants under saline condition. The complete experiment had a randomized block design, where three replications for 
each treatment were present under controlled conditions. Inoculum preparation was conducted by cultivating of wild-type strain of $A$. brasilense, adapted A. brasilense and Saccharomyces cerevisiae individual in LB broth at $28 \pm 2{ }^{\circ} \mathrm{C}$ and $150 \mathrm{rpm}$ for $48 \mathrm{~h}$. Bacterial cells were harvested by centrifugation at $10000 \mathrm{rpm}$ for 5 min and the supernatant was discarded. The pellet was washed twice with sterile distilled water and resuspended in sterile distilled water to get approximately $10^{8} \mathrm{CFU} / \mathrm{mL}$. Co-inoculants were prepared by mixing previously prepared single inoculants at 1:1 rate. Plant inoculation was carried out by dipping seedling roots three times in broth inoculants before transplanting them in the pots. For non-inoculated control, seedling roots were dipped three times in sterile distilled water [16]. Seedlings of tomato cv. Alisa were transplanted into $25 \mathrm{~cm}$ diameter black polyethylene bags filled with $7 \mathrm{~kg}$ of non-sterile sandy soil. Pots experiments plan was based on six treatments as follows:

1-Control without any inoculation $(200 \mathrm{mM} \mathrm{NaCl})$

2-Inoculation with wild type strain of $A$. brasilense (W)

3-Co-inoculation with wild type strain of A. brasilense and Saccharomyces cerevisiae (W+S)

4-Inoculation with Saccharomyces cerevisiae (S)

5-Inoculation with adapted strain of $A$. brasilense (A)

6-Co-inoculation with adapted strain of $A$. brasilense and $S$. cerevisiae (A+S)

A saline soil is generally defined as one in which the electrical conductivity (EC) of the saturation extract $\left(\mathrm{EC}_{\mathrm{e}}\right.$ ) in the root zone exceeds $4 \mathrm{dS} \mathrm{m}^{-1}$ (approximately $40 \mathrm{mM} \mathrm{NaCl}$ ) at $25^{\circ} \mathrm{C}$ and has an exchangeable sodium of $15 \%$ [17]. In this sense to induce salinity-resulted osmotic stress, all pots were watered by $200 \mathrm{mM} \mathrm{NaCl}$ dissolved in Hoagland's nutrient solution [18]. Plants were grown under greenhouse condition for 90 days to evaluate the effect of applied inoculants on biometric parameters (shoot and root length, fresh and dry weight of plants (in a forced-air oven at $70^{\circ} \mathrm{C}$ for $72 \mathrm{~h}$ to constant weight) and fresh weight of fruits.

\subsection{Determination of Photosynthetic Pigments and Ion Content in Tomato Leaves}

For estimation of photosynthetic pigments content (chlorophyll a, b and carotenoids), about $1 \mathrm{~g}$ of small leaves of each plant (after 90 days of sowing) were homogenized in $8 \mathrm{~mL}$ acetone $(80 \%)$, and then centrifuged at $10,000 \mathrm{rpm}$ for $10 \mathrm{~min}$ at $4{ }^{\circ} \mathrm{C}$. The absorbance of the supernatant was measured using a UV/VIS spectrophotometer in the range of $450-750 \mathrm{~nm}$ against ethanol as a blank test [19]. To ion content dried leaves were ground and acid digested for the analysis of cations and phosphorus. Leaf digestions was analyzed using atomic absorption spectrometry [19]. Leaf $\mathrm{N}$ was measured using a microKjeldahl procedure.

\subsection{Determination of Free Proline Content and Total Soluble Sugar}

$0.2 \mathrm{~g}$ of fresh leaves were frozen and homogenized in $4 \mathrm{~mL}$ sulfosalicylic acid (3\%), and the homogenates were centrifuged at $11,000 \times \mathrm{g}$ for $15 \mathrm{~min}$. Equal volumes from the supernatant, glacial acetic acid and acidic ninhydrin were mixed and incubated at $90^{\circ} \mathrm{C}$ for $1 \mathrm{~h}$ in a water bath. The mixture has been transferred to ice to stop the reaction, and then $1 \mathrm{ml}$ of toluene was added. After vortexing, the solution was left at room temperature for separating the two phases. The absorbance of the upper phase (toluene) was measured at $520 \mathrm{~nm}$. Proline content (mg/g FW) was calculated using the standard curve [10]. Total soluble sugars were determined according to phenol sulfuric acid method [19].

After 90 days of cultivation, $0.5 \mathrm{~g}$ of fresh leaves of each plant was homogenized in deionized water; and then filtered. $1 \mathrm{~mL}$ of the resulted extract was mixed with $1 \mathrm{~mL} \mathrm{5 \%}$ phenol and $5 \mathrm{~mL}$ sulfuric acid $98 \%$. After one hour, the mixture's absorbance of mixture was recorded at $490 \mathrm{~nm}$ by spectrophotometer, and soluble sugar content was calculated against the glucose standard curve. 


\subsection{Statistical Analysis}

Statistical analysis was performed using SPSS software ver. 21.0 (SPSS, Inc., USA) for windows. The data were processed using analysis of variance (ANOVA) and Turkey's multiple range tests $(p<0.05)$ according to Steel et al. [20]. The results were expressed as mean of triplicates \pm standard division (SD).

\section{Results}

\subsection{Effect of Salinity on the Growth and Biochemical Parameters of A. brasilense}

Our results showed that $A$. brasilense exhibited an increase in the growth rate combined with the increase of salt concentration up to $5 \% \mathrm{NaCl}$, and then the growth rate was decreased after that with increasing $\mathrm{NaCl}$ concentrations above 5\% (Fig. 1). The highest significant $(p<0.05)$ growth rate was recorded at $5 \% \mathrm{NaCl}$, while the lowest $(p<0.05)$ significant growth was observed at $0 \% \mathrm{NaCl}$. No significant difference was observed between the growth rates at $1 \%, 3 \%$ and $7 \% \mathrm{NaCl}(p \leq 0.05)$.

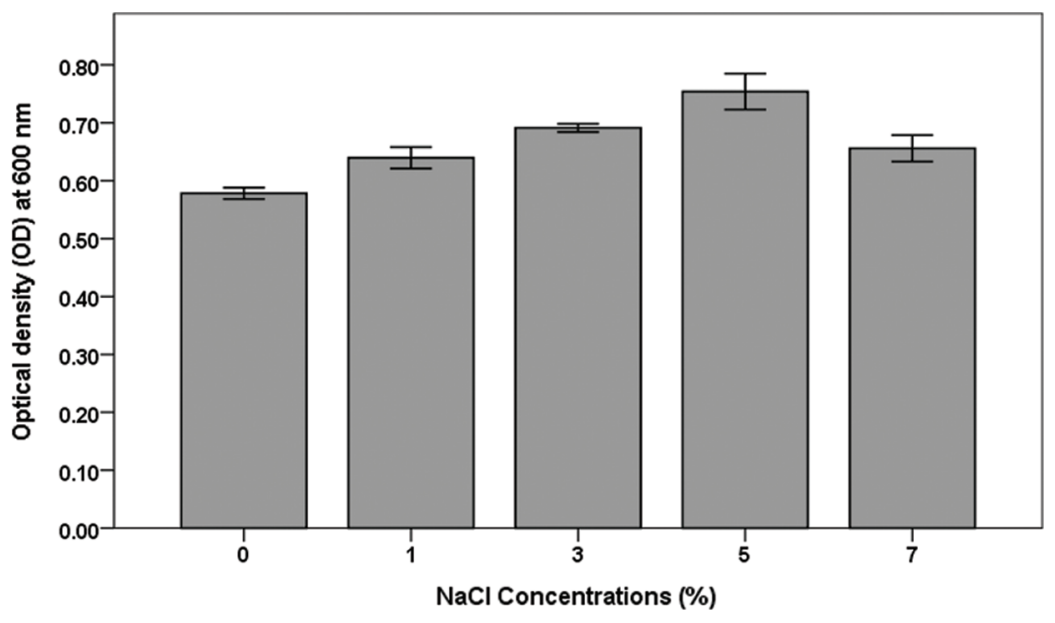

Figure 1: Growth of adapted $A$. brasilense at different $\mathrm{NaCl}$ concentrations

The results of the effects of different $\mathrm{NaCl}$ concentrations on ARA activity (nitrogenase activity), IAA and the production of exopolysaccharides (EPS) are shown in Tab. 1. ARA activity was increased with an increase of $\mathrm{NaCl}$ concentration up to $3 \%$. Generally, $3 \%$ and $5 \% \mathrm{NaCl}$ have been significantly $(p<0.05)$ among different salt concentrations, which enhanced the ARA activity compared to $0 \% \mathrm{NaCl}$. No significant difference $(p<0.05)$ between both $1 \%$ and $7 \% \mathrm{NaCl}$ with $0 \% \mathrm{NaCl}$ was observed. On the other hand, the highest production of IAA $(43.2 \pm 3.83 \mu \mathrm{g} / \mathrm{mL})$ was recorded at $3 \% \mathrm{NaCl}$, while the lowest IAA production $(29.1 \pm 2.85 \mu \mathrm{g} / \mathrm{mL})$ was observed at $7 \% \mathrm{NaCl}$ concentrations (Tab. 1). On the other hand, the results showed that increasing $\mathrm{NaCl}$ concentration increased EPS production by adapted $A$. brasilense. The highest significant $(p<0.01)$ of EPS $(646.73 \pm 8.72 \mu \mathrm{g} / \mathrm{mL})$ was recorded at $5 \% \mathrm{NaCl}$, after that it was slightly decreased. The lowest significant $(p<0.01)$ production of EPS $(380.26 \pm 10.75 \mu \mathrm{g} / \mathrm{mL})$ was observed in the absence of salt $(0 \% \mathrm{NaCl})$.

\subsection{Effect of Adapted A. brasilense on Vegetative Parameters and Yield of Tomato}

The effect of adapted $A$. brasilense on the tomato plant's growth promotion was evaluated under salt stress condition, and the result has presented in Tab. 2 and Fig. 2. All vegetative parameters (plant height, root length, fresh and dry weight, and fruit yield) of tomato plants showed significant differences between the treatments. Among all treatments, plants co-inoculated with adapted strain of A. brasilense and $S$. cerevisiae $(\mathrm{A}+\mathrm{S})$ showed the highest significant $(p<0.01)$ increase in all growth parameters and yield 
as compared with un-inoculated control plants. Plants inoculated with adapted strain of $A$. brasilense (A) alone, also demonstrated a significant increase in all growth parameters and yield of tomato, except plant high. In contrast, the plants inoculated with wild type $A$. brasilense alone (W) did not show any significant differences with control in all measured parameters.

Table 1: Effect of salt concentration on ARA activity, IAA and EPS of adapted A. brasilense

\begin{tabular}{llll}
\hline \multirow{2}{*}{$\mathrm{NaCl}$ Concentrations (\%) } & \multicolumn{3}{c}{ PGPR Traits } \\
\cline { 2 - 4 } & $\begin{array}{l}\text { ARA activity } \\
\left(\mu \mathrm{moL} \text { of } \mathrm{C}_{2} \mathrm{H}_{4} / \mathrm{mg} \text { protein } / \mathrm{h}\right)\end{array}$ & $\begin{array}{l}\text { IAA } \\
(\mu \mathrm{g} / \mathrm{mL})\end{array}$ & EPS $(\mu \mathrm{g} / \mathrm{mL})$ \\
\hline 0 & $13.65 \pm 0.86^{\mathrm{bc}}$ & $35.6 \pm 0.91^{\mathrm{b}}$ & $380.26 \pm 10.75^{\mathrm{d}}$ \\
1 & $15.43 \pm 1.00^{\mathrm{b}}$ & $40.7 \pm 1.01^{\mathrm{ab}}$ & $526.43 \pm 5.8^{\mathrm{c}}$ \\
3 & $19.33 \pm 0.60^{\mathrm{a}}$ & $43.2 \pm 3.83^{\mathrm{a}}$ & $590.1 \pm 19.91^{\mathrm{b}}$ \\
5 & $17.46 \pm 0.83^{\mathrm{ab}}$ & $42.7 \pm 1.40^{\mathrm{a}}$ & $646.73 \pm 8.72^{\mathrm{a}}$ \\
7 & $13.16 \pm 0.30^{\mathrm{c}}$ & $29.1 \pm 2.85^{\mathrm{c}}$ & $493.13 \pm 20.45^{\mathrm{c}}$ \\
\hline
\end{tabular}

Note: Values represent the means of three replicates \pm SD; different letters in a column are significantly different according to Tukey's HDS post hoc test $(p<0.05)$.

Table 2: Effect of bio-inoculants on growth and productivity of tomato plants under salinity condition

\begin{tabular}{llllll}
\hline Treatments & \multicolumn{5}{c}{ Parameters } \\
\cline { 2 - 6 } & $\begin{array}{l}\text { Plant heigh } \\
(\mathrm{cm})\end{array}$ & $\begin{array}{l}\text { Root length } \\
(\mathrm{cm})\end{array}$ & $\begin{array}{l}\text { Fresh weight } \\
(\mathrm{g} / \text { plant })\end{array}$ & $\begin{array}{l}\text { Dry weight } \\
(\mathrm{g} / \text { plant })\end{array}$ & $\begin{array}{l}\text { Fruit yield } \\
(\mathrm{g} / \text { plant })\end{array}$ \\
\hline Control & $43.3 \pm 1.5^{\mathrm{c}}$ & $29.6 \pm 2.0^{\mathrm{d}}$ & $101.6 \pm 2.50^{\mathrm{e}}$ & $23.0 \pm 1.0^{\mathrm{d}}$ & $42.0 \pm 3.0^{\mathrm{d}}$ \\
$\mathrm{W}$ & $43.0 \pm 2.6^{\mathrm{c}}$ & $29.6 \pm 1.5^{\mathrm{d}}$ & $115.3 \pm 11.6^{\mathrm{e}}$ & $22.6 \pm 1.5^{\mathrm{d}}$ & $46.6 \pm 5.0^{\mathrm{d}}$ \\
$\mathrm{W}+\mathrm{S}$ & $72.0 \pm 1.0^{\mathrm{b}}$ & $37.0 \pm 2.6^{\mathrm{c}}$ & $195.6 \pm 15.8^{\mathrm{c}}$ & $39.3 \pm 1.5^{\mathrm{c}}$ & $292.6 \pm 6.8^{\mathrm{c}}$ \\
$\mathrm{S}$ & $47.3 \pm 4.1^{\mathrm{c}}$ & $34.0 \pm 1.0^{\mathrm{cd}}$ & $163.6 \pm 5.10^{\mathrm{d}}$ & $33.3 \pm 1.5^{\mathrm{c}}$ & $142.3 \pm 9.5^{\mathrm{d}}$ \\
$\mathrm{A}$ & $78.0 \pm 4.0^{\mathrm{b}}$ & $43.6 \pm 2.0^{\mathrm{b}}$ & $317.3 \pm 6.80^{\mathrm{b}}$ & $51.3 \pm 2.0^{\mathrm{b}}$ & $859 \pm 87.7^{\mathrm{b}}$ \\
$\mathrm{A}+\mathrm{S}$ & $115 \pm 7.0^{\mathrm{a}}$ & $52.6 \pm 2.0^{\mathrm{a}}$ & $382.0 \pm 11.3^{\mathrm{a}}$ & $70.6 \pm 4.7^{\mathrm{a}}$ & $1166.6 \pm 46.2^{\mathrm{a}}$ \\
\hline
\end{tabular}

Note: Values represent the means of three replicates \pm SD; different letters in a column are significantly different according to Tukey's HDS post hoc test $(p<0.05)$.

However, co-inoculation with wild type and $S$. cerevisiae $(\mathrm{W}+\mathrm{S})$ significantly $(p<0.05)$ enhanced growth parameters and fruit yield of tomato when compared to control. Also, the plants treated with $S$. cerevisiae (S) alone showed significant increase in fresh and dry weight, while did not show significant plant high, root length and fruit yield of tomato compared with control. These results revealed that the growth characteristics (plant high, root length, fresh and dry weight and fruit yield) of tomato plants coinoculated with $(\mathrm{A}+\mathrm{S})$ had been increased to $1.65,0.77,2.78,2.06$ and 26.7 folds respectively as compared to control, under salt stress condition.

\subsection{Photosynthetic Pigments (Chlorophyll $a, b$ and Carotenoids)}

The results of the effect of PGPR inoculants on photosynthetic pigments (Chlorophyll a, b and carotenoid) in tomato leaves pointed to the existence of significant differences among treatments (Fig. 3). All treatments, except inoculation with wild type strain of $A$. brasilense (W), significantly stimulated 
photosynthetic pigments' content under $4 \% \mathrm{NaCl}$ concentration. Plants co-inoculated with an adapted strain of $A$. brasilense and $S$. cerevisiae $(\mathrm{A}+\mathrm{S})$ showed the highest significant $(p<0.05)$ values of chlorophyll a, b and carotenoid which were $1.35 \pm 0.08,0.45 \pm 0.02$ and $0.41 \pm 0.02 \mathrm{mg} / \mathrm{g}$ fresh weight, respectively, as compared to un-inoculated plants, followed by plants inoculated with an adapted strain of $A$. brasilense alone (A). The lowest significant $(p<0.05)$ chlorophyll content was recorded with the wild type of strain A. brasilense (W), which was non-significant with un-inoculated control. No significant difference between plants treated with $S$. cerevisiae (S) alone and plants co-inoculated with both $S$. cerevisiae and wild type of $A$. brasilense $(\mathrm{W}+\mathrm{S})$ in chlorophyll a, $\mathrm{b}$ and carotenoid contents was observed.

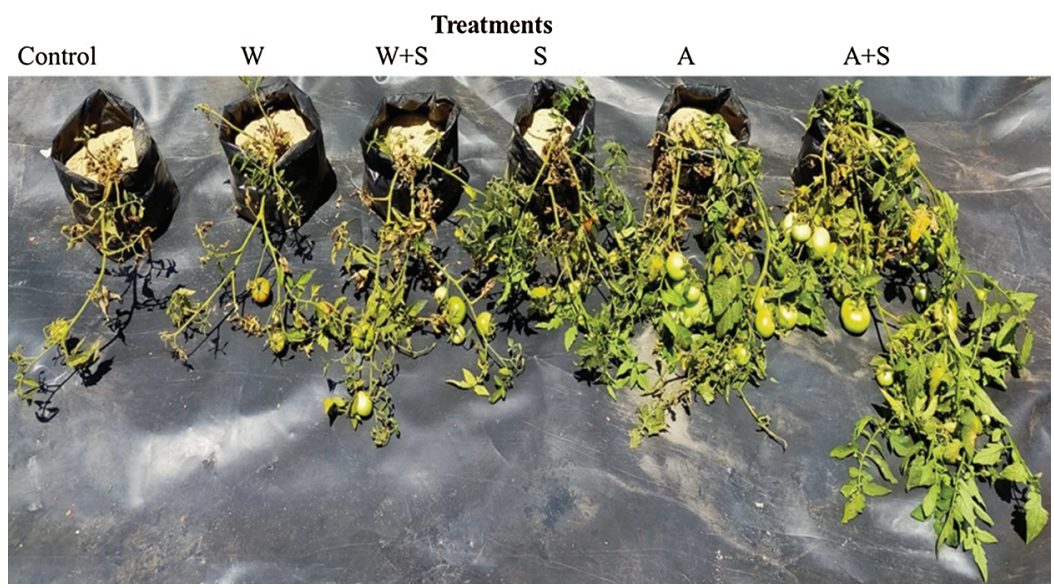

Figure 2: Effect of $A$. brasilense inoculants on the growth of tomato plants under salinity stress

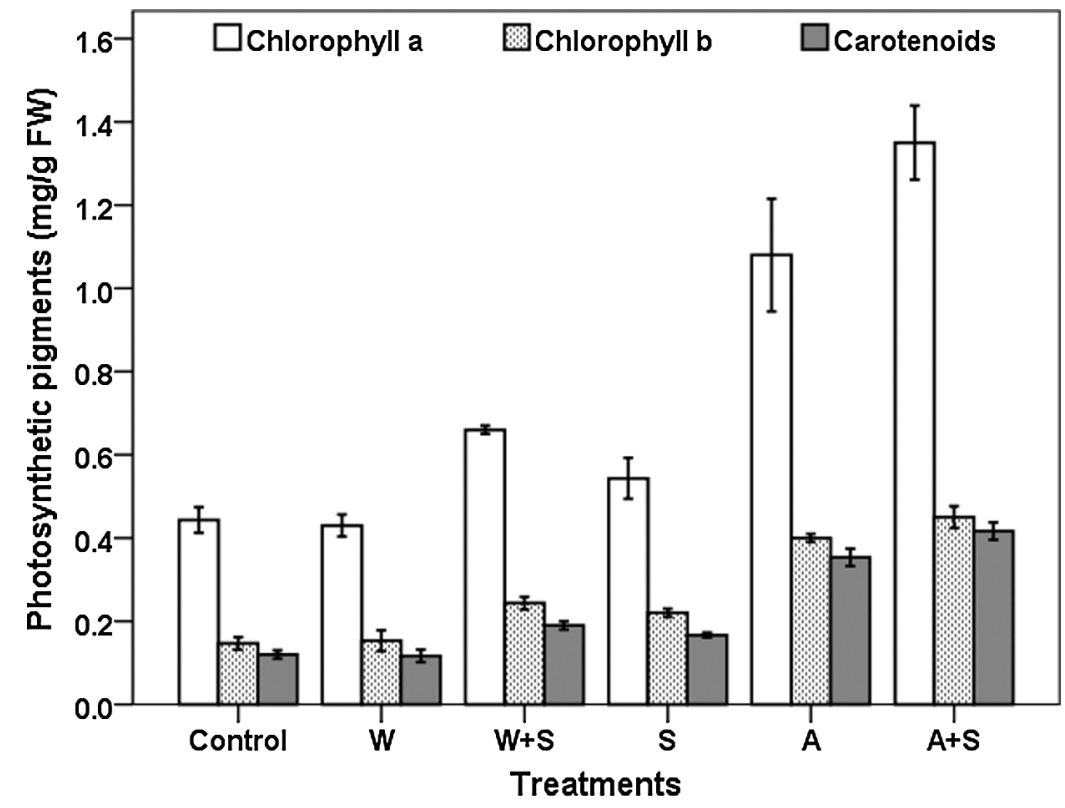

Figure 3: Effect of bacterial inoculants on photosynthetic pigments of tomato plants under salt stress condition 


\subsection{Proline and Total Soluble Sugar (TSS) Content}

Application of bacterial inoculants had significant impacts on proline and total soluble sugar content in tomato plant leaves under salinity condition (Figs. 4a and 4b). Proline content was significantly $(p<0.01)$ increased in leaves of plant treated with an adapted strain of $A$. brasilense, whether in the case of single inoculant (A) or co-inoculant with an adapted strain of $A$. brasilense and $S$. cerevisiae $(\mathrm{A}+\mathrm{S})$, in comparison to un-inoculated control. No significant difference in proline content between plants treated with the wild type strain of $A$. brasilense and $S$. cerevisiae in both single inoculation and co-inoculation and un-treated plants was observed. On the other hand, all treatments, except inoculation with the wild type of strain $A$. brasilense (W), were significantly $(p<0.05)$ stimulated TSS content in tomato leaves in comparison to control. Plants treated with both adapted strain of A. brasilense and S. cerevisiae (A+S) exhibited the highest significant $(p<0.01)$ leaf contents of both proline and TSS, followed by plant treated with an adapted strain of $A$. brasilense alone (A) when compared with un-treated plants.
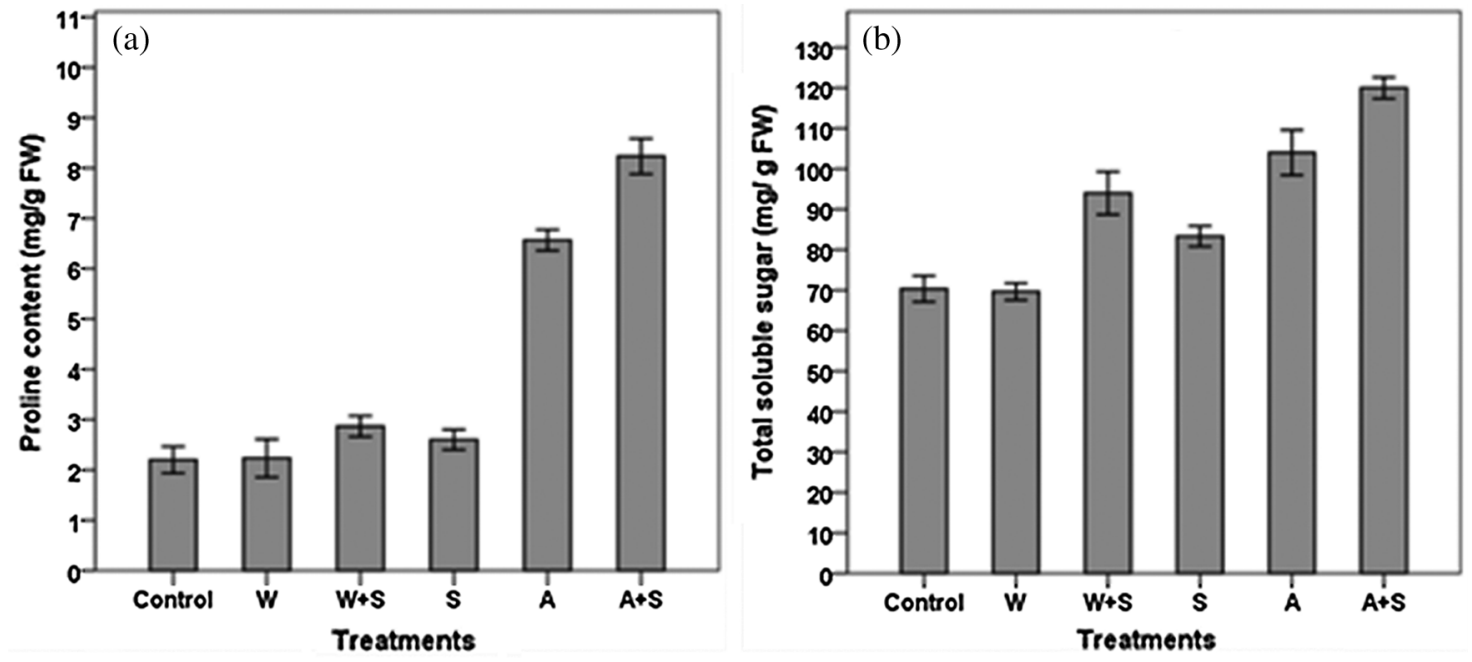

Figure 4: Effect of bacterial inoculants on proline content (a), and total soluble sugar content (b) in leaves of tomato plants under salt stress condition

\subsection{Leaf Ion Contents}

Data illustrated in Fig. 5 exhibit that leaf ion contents ( $\mathrm{Na}, \mathrm{Ca}, \mathrm{Mg}, \mathrm{K}, \mathrm{P}$ and $\mathrm{N}$ ) were significantly affected by microbial treatments. Leaf $\mathrm{Na}^{+}$content was significantly $(p<0.01)$ decreased in tomato plants treated with an adapted strain of $A$. brasilense whether alone (A) or combined with $S$. cerevisiae $(\mathrm{A}+\mathrm{S})$ in comparison to control. On the other hand, all other ions have been significantly $(p<0.01)$ increased in plant treated with $\mathrm{A}$ and $\mathrm{A}+\mathrm{S}$. A+S treated plants showed the lowest significant $(p<0.01) \mathrm{Na}^{+}$content and the highest significant $(p<0.01)$ content of all other ions as compared to un-treated plants. There was no significant difference between the wild strain of $A$. brasilense treated plants $(\mathrm{W})$ and un-treated plants for all ions content. $\mathrm{Ca}, \mathrm{Mg}, \mathrm{P}$ and $\mathrm{N}$ leaf contents were significantly increased in plant coinoculated with a wild strain of $A$. brasilense and $S$. cerevisiae $(\mathrm{W}+\mathrm{S})$ and plant treated with $S$. cerevisiae alone (S) as compared to control, without significant difference between the two treatments $\mathrm{S}$ and $\mathrm{W}+\mathrm{S}$. Co-inoculation with $\mathrm{W}+\mathrm{S}$ led to significant increase of $\mathrm{K}$ content and a significant decrease of $\mathrm{Na}$ content, while inoculation with $\mathrm{S}$ alone did not show any significant difference in $\mathrm{K}$ and $\mathrm{Na}$ content compared to un-inoculated control. 


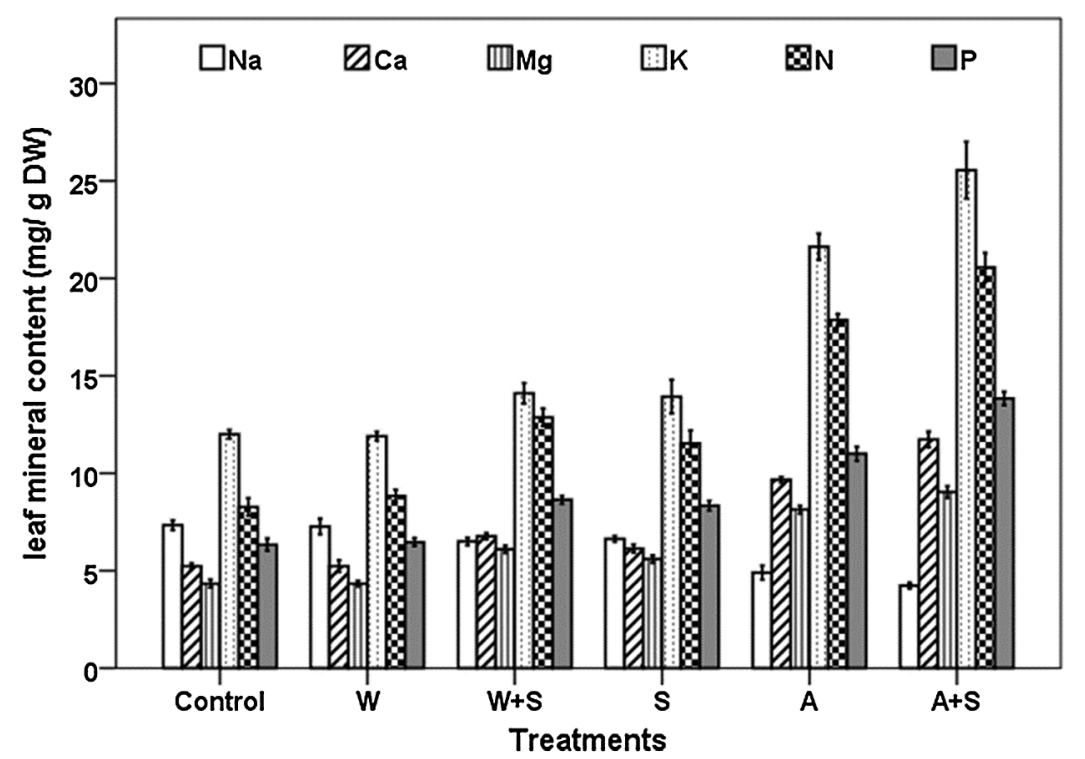

Figure 5: Effect of bacterial inoculants on leaf mineral contents under salt stress conditions

\section{Discussion}

A.brasilensis based biofertilizers, alone or in combination with other microbial-based products, show promise as alternatives to chemical fertilization, especially in salinity affected areas [1,18]. Our results showed that co-inoculation with (A. brasilense strain N040 and S. cerevisiae) clearly benefited the tomato plant's by enhancing growth, productivity, biochemical parameters (proline and chlorophyll) and leaf $\mathrm{Na}^{+}$ reduction. Extreme accumulation of sodium ion $\left(\mathrm{Na}^{+}\right)$in plants could affect different mineral nutrients by limitation of their uptake, transport and distribution, and cause to nutrient imbalance, a decrease of $\mathrm{K}^{+}$ and $\mathrm{Ca}^{2+}$ uptake and induce $\mathrm{Na}^{+}$toxicity in plant [1,10]. Our results indicated that tomato plants' inoculation with adapted strain of $A$. brasilense and S.cereviseae induced significant decrease in $\mathrm{Na}^{+}$and increase in $\mathrm{K}, \mathrm{Ca}, \mathrm{Mg}, \mathrm{P}$ and $\mathrm{N}$ content in tomato leaves, under salinity stress. Similarly, A. brasilense significantly relieved the salinity stress in white clover plants, where shoot fresh and shoot dry weight and root dry weight of inoculated plants were significantly increased compared to un-inoculated plants under different $\mathrm{NaCl}$ concentrations [18]. In this concern, tomato plants treated with adapted Pseudomonas species to $6 \% \mathrm{NaCl}$ concentration showed an increase of tomato growth parameters such as root length, shoot length, fresh weight, and dry weight in the presence of $2 \% \mathrm{NaCl}$ concentration [21]. Inoculation of tomato roots with Azotobacter chroococcum 76A led to promoting of salt stress tolerance, fruit number/plant, fruit weight, shoot dry weight and nutrient uptake efficiency under severe salinity [2]. Catharanthus roseus plants treated with mutant strains mixture of P. stutzeri, P. mendocina, B. flexus and $B$. subtilis, showed a significant increase in length, fresh and dry weight of root and shoot as compared to un-inoculated plants, and plants treated with such mixture of wild strains, under $4 \% \mathrm{NaCl}$ concentration [16]. On the other hand, the increase of chlorophyll and carotenoid content in PGPR-inoculated plant leaves under salt stress condition has been reported by numerous researchers [6,22-24]. In this sense, in our study, increase of chlorophyll in the tomato plants inoculated with A. brasilense strain N040 and $S$. cerevisiae could be results of inhibition $\mathrm{Na}$ transport, thus improving $\mathrm{Mg}^{2+}$ ions absorption leading to intensifying chlorophyll synthesis under salt stress conditions [25]. In this sense, the PGPR could enhance chlorophyll pigments in plants via increase of proline levels in plant tissues, which decreased chlorophyll degradation [26]. Another option is that the increased chlorophyll content in tomato plantsco-inoculated exposed to salts stress may be due to the increased leaf area compared to un-inoculated 
plants where photosynthetic leaf area reduced due to stress (Fig. 2) [21]. The accumulation of proline in plant tissues is an adaptive and common response of plants to salinity stress, which assists in osmotic adjustment and scavenging of hydroxyl radicals, thus protecting intracellular macromolecule's structure and cell membranes stabilization $[23,27]$. Under salinity stress, proline play a vital role in reducing the oxidative stress caused by salinity through several strategies such as regulation of cytosolic acidity, maintenance of proteins, ROS scavenging and reduced lipid peroxidation [5]. In the present study, both proline and TSS contents were increased in tomato plants treated with an adapted strain of $A$. brasilense under salt stress conditions, suggesting that this strain may stimulate plant growth under salinity condition inducing metabolic defense mechanisms in plants. Similarly, halotolerant Bacillus aryabhattai $\mathrm{H} 19-1$ and B. mesonae $\mathrm{H} 20-5$ increased proline and total soluble sugar contents, as well as induction of salinity tolerance in tomato plants [10,28]. Our results suggested that the adapted strain of $A$. brasilense and S.cereivisae could play a vital role in alleviating salinity stress and enhancing nutrients uptake by plants, under salinity stress. In this regard, the tomato plant's coinoculation with Bacillus aryabhattai $\mathrm{H} 19-1$ and B. mesonae $\mathrm{H} 20-5$ induced the salinity tolerance in plants through $\mathrm{Ca}^{2+}$ accumulation, where $\mathrm{Ca}^{2+}$ accumulation contributed to osmoregulation by enhancing water uptake efficiency and increasing proline [10]. Finally, we suggest, coinoculation of A. brasilense and S.cereivisae induced the activation of important biochemical and physiological mechanism in tomato plants under salt stress.

\section{Conclusion}

The used PGPR strain in the present study was adapted to $7 \% \mathrm{NaCl}$ concentration, which can enhance tomato plant growth and yield in the presence of $200 \mathrm{mM} \mathrm{NaCl}$, as well as alleviate harmful impact caused by salt stress. From the study, we can conclude that co-inoculation A. brasilense with $S$. cerevisiae exhibited grateful results in improving tomato plant growth and yield under salinity stress. Our results showed that co-inoculation with (A. brasilense strain N040 and $S$. cerevisiae) clearly benefited the tomato plant's by enhancing growth, productivity, biochemical parameters (proline and chlorophyll) and leaf $\mathrm{Na}^{+}$reduction. Though much more in-depth study is needed to find out the importance of these bacteria's in plantmicroorganisms interaction under salinity stress.

Authors' Contributions: Ali Abdelmoteleb and Ahmed Mohamed Elbaalawy conceived and designed the research. Daniel Gonzalez-Mendoza analyzed the experimental data and wrote the manuscript. All authors discussed the results and commented on the manuscript.

Funding Statement: This work was funded by the Faculty of Agriculture, Menoufia University (Grant No. 000212).

Conflicts of Interest: The authors declare that they have no interest in reporting regarding the present study.

\section{References}

1. Kumar, A., Patel, J. S., Meena, V. S., Ramteke, P. W. (2019). Plant growth-promoting rhizobacteria: Strategies to improve abiotic stresses under sustainable agriculture. Journal of Plant Nutrition, 42(11-12), 1402-1415. DOI 10.1080/01904167.2019.1616757.

2. van Oosten, M. J., Di Stasio, E., Cirillo, V., Silletti, S., Ventorino, V. et al. (2018). Root inoculation with Azotobacter chroococcum 76A enhances tomato plants adaptation to salt stress under low $\mathrm{N}$ conditions. BMC Plant Biology, 18(1), 205. DOI 10.1186/s12870-018-1411-5.

3. Suhail, F. M., Mahdi, I. A. (2011). Response of Azospirillum brasilense bacteria to the types and concentrations of different salts. Bulletin of University of Agricultural Sciences and Veterinary Medicine Cluj-Napoca-Agriculture, 68(1), 356-362. DOI 10.15835/buasvmcn-agr:6466. 
4. Shrivastava, P., Kumar, R. (2015). Soil salinity: A serious environmental issue and plant growth promoting bacteria as one of the tools for its alleviation. Saudi Journal Bioloical Sciences, 222(2), 123-31. DOI 10.1016/ j.sjbs.2014.12.001.

5. Abbas, R., Rasul, S., Aslam, K., Baber, M., Shahid, M. et al. (2019). Halotolerant PGPR: A hope for cultivation of saline soils. Journal of King Saud University-Science, 31(4), 1195-1201. DOI 10.1016/j.jksus.2019.02.019.

6. Abdel Motaleb, N. A., Abd Elhady, S. A., Ghoname, A. A. (2020). AMF and Bacillus megaterium neutralize the harmful effects of salt stress on bean plants. Gesunde Pflanzen, 72(1), 29-39. DOI 10.1007/s10343-019-00480-8.

7. Viscardi, S., Ventorino, V., Duran, P., Maggio, A., De Pascale, S. et al. (2016). Assessment of plant growth promoting activities and abiotic stress tolerance of Azotobacter chroococcum strains for a potential use in sustainable agriculture. Journal of Soil Science and Plant Nutrition, 16(3), 848-863. DOI 10.4067/S071895162016005000060.

8. Acosta-Motos, J. R., Penella, C., Hernández, J. A., Díaz-Vivancos, P., Sánchez-Blanco et al. (2020). Towards a sustainable agriculture: Strategies involving phytoprotectants against salt stress. Agronomy, 10(2), 1-32. DOI 10.3390/agronomy10020194.

9. Misra, S., Chauhan, P. S. (2020). ACC deaminase-producing rhizosphere competent Bacillus spp. mitigate salt stress and promote Zea mays growth by modulating ethylene metabolism. 3 Biotech, 10(3), 1-14. DOI 10.1007/s13205-020-2104-y.

10. Yoo, S. J., Weon, H. Y., Song, J., Sang, M. K. (2019). Induced tolerance to salinity stress by halotolerant bacteria Bacillus aryabhattai $\mathrm{H} 19-1$ and B. mesonae $\mathrm{H} 20-5$ in tomato plants. Journal of Microbiology and Biotechnology, 29(7), 1124-1136. DOI 10.4014/jmb.1904.04026.

11. Farhangi-Abriz, S., Tavasolee, A., Ghassemi-Golezani, K., Torabian, S., Monirifar, H. et al. (2020). Growthpromoting bacteria and natural regulators mitigate salt toxicity and improve rapeseed plant performance. Protoplasma, 257(4), 1035-1047. DOI 10.1007/s00709-020-01493-1.

12. Ahmed, N. U., Mahmud, N. U., Zaman, M. A. U., Ferdous, Z., Halder, S. C. (2017). Effect of different salinity level on tomato (Lycopersicon esculentum) production under climate change condition in Bangladesh. Annual Research and Review in Biology, 13(3), 1-9. DOI 10.9734/ARRB/2017/33613.

13. Puranik, S., Shaligram, S., Paliwal, V., Raje, D. V., Kapley, A. et al. (2012). Demonstration of sequential adaptation strategy for developing salt tolerance in bacteria for wastewater treatment: A study using Escherichia coli as model. Bioresource Technology, 121, 282-289. DOI 10.1016/j.biortech.2012.06.037.

14. Khamna, S., Yokota, A., Peberdy, J. F., Lumyong, S. (2010). Indole-3-acetic acid production by streptomyces sp. isolated from some Thai medicinal plant rhizosphere soils. EurAsian Journal of Biosciences, 32, 23-32. DOI 10.5053/ejobios.2010.4.0.4.

15. Saad, M. M. G., Kandil, M., Mohammed, Y. M. M. (2020). Isolation and identification of plant growth-promoting bacteria highly effective in suppressing root rot in fava beans. Current Microbiology, 77, 2155-2165. DOI 10.1007/s00284-020-02015-1.

16. Hingole, S. S., Pathak, A. P. (2016). Saline soil microbiome: A rich source of halotolerant PGPR. Journal of Crop Science and Biotechnology, 19(3), 231-239. DOI 10.1007/s12892-016-0035-2.

17. Shrivastava, P., Kumar, R. (2015). Soil salinity: A serious environmental issue and plant growth promoting bacteria as one of the tools for its alleviation. Saudi Journal of Biological Sciences, 22(2), 123-131. DOI 10.1016/j.sjbs.2014.12.001.

18. Khalid, M., Bilal, M., Hassani, D., Iqbal, H. M. N., Wang, H. et al. (2017). Mitigation of salt stress in white clover (Trifolium repens) by Azospirillum brasilense and its inoculation effect. Botanical Studies, 58(1), 5. DOI 10.1186/ s40529-016-0160-8.

19. Dimkpa, C., Weinand, T., Asch, F. (2009). Plant-rhizobacteria interactions alleviate abiotic stress conditions. Plant, Cell \& Environment, 32(12), 1682-1694. DOI 10.1111/j.1365-3040.2009.02028.x.

20. Steel, R. G., Torrie, J. H., Dickey, D. A. (1997). Principles and procedures of statistics. A biometrical spproach, 3rd edition. New York, USA: McGraw Hill Book Co., Inc.

21. Tank, N., Saraf, M. (2010). Salinity-resistant plant growth promoting rhizobacteria ameliorates sodium chloride stress on tomato plants. Journal of Plant Interactions, 5(1), 51-58. DOI 10.1080/17429140903125848. 
22. Velázquez-Márquez, S., Conde-Martínez, V., Trejo, C., Delgado-Alvarado, A., Carballo, A. et al. (2015). Effects of water deficit on radicle apex elongation and solute accumulation in Zea mays L. Plant Physiology and Biochemistry, 96, 29-37. DOI 10.1016/j.plaphy.2015.07.006.

23. Hahm, M. S., Son, J. S., Hwang, Y. J., Kwon, D. K., Ghim, S. Y. (2017). Alleviation of salt stress in pepper (Capsicum annum L.) plants by plant growth-promoting rhizobacteria. Journal of Microbiology and Biotechnology, 27(10), 1790-1797. DOI 10.4014/jmb.1609.09042.

24. Akram, W., Aslam, H., Ahmad, S. R., Anjum, T., Yasin, N. A. et al. (2019). Bacillus megaterium strain A12 ameliorates salinity stress in tomato plants through multiple mechanisms. Journal of Plant Interactions, 14(1), 506-518. DOI 10.1080/17429145.2019.1662497.

25. Chowdhury, S. P., Nagarajan, T., Tripathi, R., Mishra, M. N., Le Rudulier, D. et al. (2007). Strain-specific salt tolerance and osmoregulatory mechanisms in Azospirillum brasilense. FEMS Microbiology Letters, 267(1), 72-79. DOI 10.1111/j.1574-6968.2006.00540.x.

26. Grover, M., Ali, S. Z., Sandhya, V., Rasul, A., Venkateswarlu, B. (2011). Role of microorganisms in adaptation of agriculture crops to abiotic stresses. World Journal of Microbiology and Biotechnology, 27(5), 1231-1240. DOI 10.1007/s11274-010-0572-7.

27. Rabie, G. H., Almadini, A. M. (2005). Role of bioinoculants in development of salt-tolerance of vicia faba plants under salinity stress. African Journal of Biotechnology, 4(3), 210-222. DOI 10.5897/AJB2005.000-3041.

28. Kaushal, M., Kaushal, R. (2015). Acetylene reductase activity and molecular characterization of plant growth promoting rhizobacteria to know efficacy in integrated nutrient management system. Indian Journal of Biotechnology, 14, 221-227. http://nopr.niscair.res.in/handle/123456789/31813. 